\title{
Intestinal permeability in children with Crohn's disease and coeliac disease
}

\author{
A D J PEARSON，E J EASTHAM，M F LAKER，A W CRAFT, R NELSON
}

\begin{abstract}
Mannitol and lactulose were used as probe molecules to measure intestinal permeability in children with active small-bowel Crohn's disease and with untreated coeliac disease. Mannitol and lactulose were administered by mouth in a moderately hypertonic solution $(580 \mathrm{mmol}$ (mosmol)/1), and results were expressed as the ratio of the molecules excreted in urine over five hours. Patients with Crohn's disease had a sixfold increase in permeability (due to increased lactulose permeability) and those with coeliac disease a fivefold increase (due to decreased mannitol permeability).

From these results the test offers potential as a noninvasive investigation in children with small-bowel disease.
\end{abstract}

\section{Introduction}

Hydrophilic molecules permeate the healthy small-bowel mucosa at rates which depend on their molecular size. ${ }^{12}$ In clinical practice various non-metabolised sugars used to study adult populations indicate that in villous atrophy there is a decreased absorption of small molecules and an increased absorption of larger molecules. ${ }^{34}$ Other studies show that the small-bowel mucosa is more permeable to large molecules in patients with eczema and food allergy ${ }^{5}$ and also during the neonatal period. ${ }^{6}$ We were interested in this technique as a non-invasive investigation for children and have evaluated two probe molecules, mannitol and lactulose, to measure intestinal permeability in normal subjects and in two differing conditions of abnormal small-bowel mucosa-untreated coeliac disease and active Crohn's disease.

\section{Patients and methods}

Thirty-one healthy children (18 boys, 13 girls) aged 2-13 years (mean 7.6 years) who had a normal growth pattern and no gastrointestinal or atopic symptoms served as controls. Eight children (five boys) aged 9-16 years (mean 12.4) with active Crohn's disease affecting the small bowel, and five children (three boys) aged 2-14 years (mean 6.5) with untreated coeliac disease were also studied. Crohn's disease was diagnosed on clinical, radiological, and histological criteria $^{7}$ and coeliac disease by clinical and histological criteria. All five patients with coeliac disease were eating a normal glutencontaining diet, had total villous atrophy on jejunal biopsy, and subsequently gave an excellent clinical response to gluten withdrawal. They had no other features to suggest any other cause for their villous atrophy.

\footnotetext{
Departments of Child Health and Clinical Biochemistry and Metabolic Medicine, Royal Victoria Infirmary, Newcastle upon Tyne NE1 4LP

A D J PEARSON, MRCP, Leukaemia Research Fund Fellow E J EASTHAM, MRCP, paediatric senior registrar M F LAKER, MD, MRCPATH, senior lecturer in clinical biochemistry A W CRAFT, MD, MRCP, consultant paediatrician R NELSON, FRCP, consultant paediatrician
}

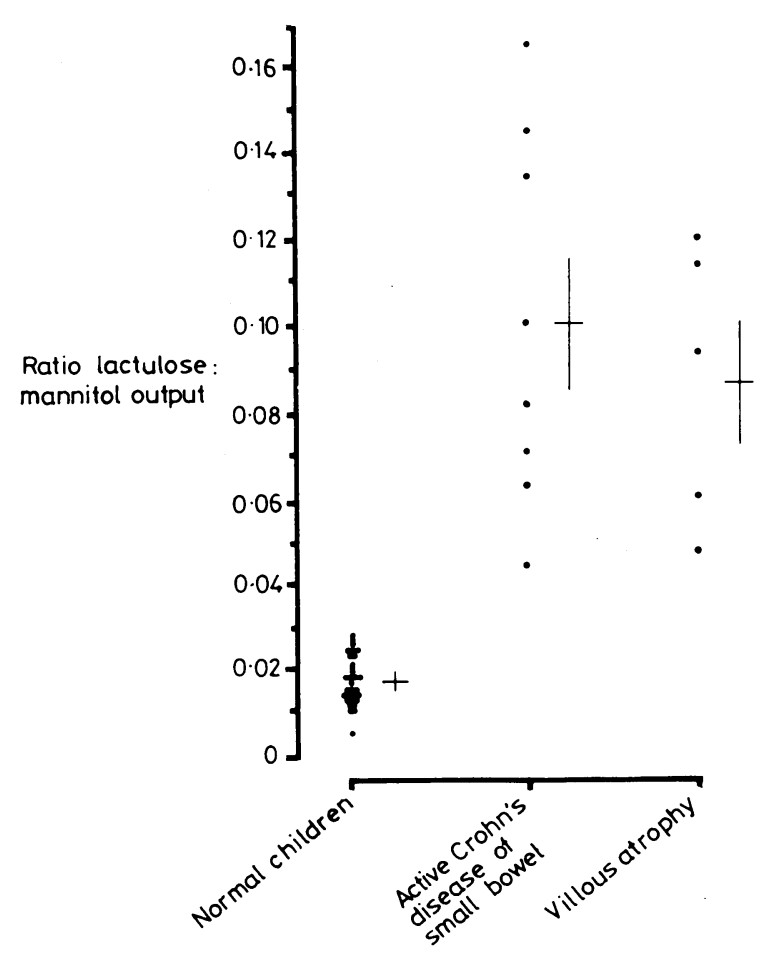

FIG 1-Ratios of five-hour urinary lactulose and mannitol excretion (mean $\pm S E)$.

After an overnight fast urine $(20 \mathrm{ml})$ was sampled for measurement of endogenous mannitol excretion. Over five minutes the child then drank a solution containing $5 \mathrm{~g}$ mannitol and $5 \mathrm{~g}$ lactulose in $65 \mathrm{ml}$ water, giving an osmolality of $580 \mathrm{mmol}(\mathrm{mosmol}) / \mathrm{kg}$. No further fluid or food was allowed for two hours. Urine was collected for five hours after ingestion, $10 \%$ methiolate was added as preservative, and after recording the volume aliquots were frozen at $-20^{\circ} \mathrm{C}$ until analysis. Urine was desalted and dried and trimethyl derivatives of the sugars prepared. Analysis was performed by gas-liquid chromatography as described, ${ }^{8} 9$ the column temperature being modified for mannitol $\left(205^{\circ} \mathrm{C}\right)$ and lactulose $\left(265^{\circ} \mathrm{C}\right), \alpha$-Methyl glucose and turanose were used as internal standards for mannitol and lactulose, respectively.

Statistical analysis was with a non-parametric Wilcoxon test.

\section{Results}

All children tolerated the test protocol well, there being no nausea, vomiting, or diarrhoea. In a very few one or two stools were subse quently looser than usual. The simple protocol did not need admission to hospital and many tests were performed at home, the parents being given written instructions.

Baseline urine specimens contained no lactulose and only small amounts of mannitol-the highest concentration being $0.66 \mathrm{mmol} / \mathrm{l}$ $(12 \mathrm{mg} / 100 \mathrm{ml})$. Healthy normal children excreted a mean of $14 \%$ of the mannitol load (range $8 \cdot 5-24.5 \%$ ) but only $0.25 \%$ of the lactulose load (range $0.065-0.45 \%$ ) in the five-hour period. Expressed as a ratio of lactulose to mannitol the mean normal urine output was 0.018 (range $0.005-0 \cdot 028$ ). Figure 1 shows the calculated ratios for the patients with Crohn's disease and coeliac disease. There was a sixfold increase in ratio in the patients with Crohn's disease and a fivefold increase in those with coeliac disease. The differences were 
statistically significant $(p<0.01)$. There was no overlap between normal and diseased children.

Analysis of individual outputs of sugar (fig 2) showed a pronounced difference between the groups. In the children with Crohn's disease there was a fourfold increase in lactulose output (mean 1.06\%; range $0 \cdot 60-1 \cdot 75 \%$ ), while their mannitol output was not significantly different from that of controls (mean $11.7 \%$; range $6 \cdot 0-21.6 \%$ ). In comparison, the coeliac group exhibited a fivefold reduction in mannitol output (mean $2.8 \%$; range $1.96-4.08 \%$ ) but a normal lactulose output (mean $0.2 \%$; range $0 \cdot 12-0 \cdot 32 \%$ ). The differences between each group were significant $(p<0 \cdot 01)$.

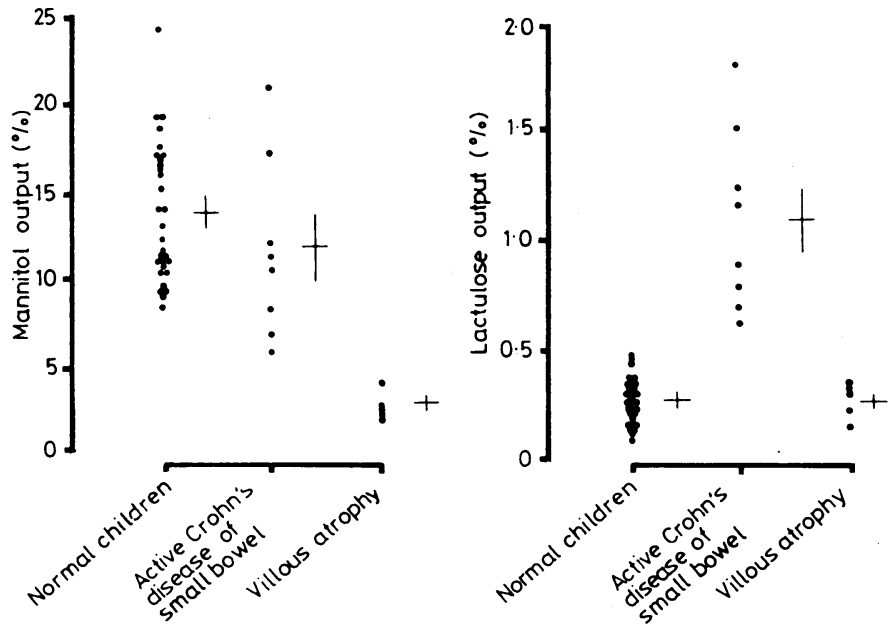

FIG 2-Urinary five-hour mannitol and lactulose output (mean $\pm \mathrm{SE}$ ).

\section{Discussion}

The probe molecules mannitol and lactulose have various properties which make them suitable for measuring intestinal permeability. They are hydrophilic and lipophobic, have negligible affinity for the monosaccharide transport system, ${ }^{10}$ and are thus absorbed passively by non-mediated means. They are non-metabolised, with almost total recovery in the urine after intravenous injection, and have a high $(>90 \mathrm{ml} / \mathrm{min})$ renal clearance..$^{10}{ }^{11}$ Though lactulose is a disaccharide it is not hydrolysed by lactase, ${ }^{12}$ and endogenous mannitol in the urine occurs in only negligible quantities. Urinary excretion should therefore mirror gastrointestinal absorption of these sugars.

Mannitol and lactulose do, however, differ in their molecular size, mannitol having a radius of $0.4 \mathrm{~nm}$ and lactulose a radius of $0.52 \mathrm{~nm}$. Hence their absorption is thought to be along different pathways. Mannitol passes through the more abundant transcellular routes of aqueous pores in the cell membrane, while lactulose passes through the fewer intercellular junctional complexes and extrusion zones at the villous tips. ${ }^{3413}$ In our children with total villous atrophy there was a significant reduction in mannitol output as a consequence of the reduced surface area-confirming adult studies. ${ }^{3}{ }^{4}$ Lactulose output, however, was not significantly altered, a finding at variance with adult studies which have shown an increased absorption of disaccharides of similar size. In those studies the osmolality of the oral solutions was much higher $(1400 \mathrm{mmol} / \mathrm{kg})$, and it has been shown that there is a correlation between hypertonicity and the amount absorbed. ${ }^{14}{ }^{15}$ Hence the changes at junctional complexes and extrusion zones in coeliac disease can apparently only be shown using very hypertonic solutions. ${ }^{11}$

There is no other description of increased absorption of disaccharides (lactulose) in active small-bowel Crohn's disease. An abnormal permeability ratio with mannitol and cellobiose was noted in five out of nine adults with predominantly jejunal disease, ${ }^{16}$ but relative sugar outputs were not mentioned. Similarly, a tendency for an increased absorption of larger molecules from a differing molecular-weight mixture of poly- ethylene glycol molecules was noted in one adult with this disease. ${ }^{17}$ The increased absorption of lactulose in our patients was presumably a result of the inflammatory process causing damage to the junctional complexes and increasing the number of extrusion zones. The changes in total villous surface area, however, were not enough to alter significantly the aqueous pore population as judged by mannitol absorption.

Any non-invasive procedure is welcomed in paediatrics. Other attempts to rely on urine collections are fraught with difficulties-for example, five-hour urinary xylose excretionand give spurious results, partly because of other variables such as gastric emptying, small-bowel transit times, and urinary excretion. The use of two sugar solutions and measurement of their ratios, however, negate these influences, and the need for strictly timed urine collections also becomes less important. Our preliminary data suggest that the intestinal permeability ratio is a sensitive indicator of small-bowel disease in children. The protocol is well tolerated, easy to perform, and may be carried out at home. Though not diagnostic of any one disease, an abnormal ratio would be an indicator to proceed with more invasive techniques. The data also suggest that the investigation may be of value in screening patients with short stature (for coeliac disease) and with recurrent abdominal pain. It may also prove useful when giving a gluten challenge test and in following the progress of patients with small-bowel Crohn's disease.

We are grateful to the Leukaemia Research Fund for the support of $\mathrm{ADJP}$ and for laboratory equipment, and to Mrs P McEwen for secretarial help.

Requests for reprints should be addressed to: Dr E J Eastham, Department of Child Health, Royal Victoria Infirmary, Queen Victoria Road, Newcastle upon Tyne NE1 4LP.

\section{References}

${ }^{1}$ Lindemann B, Solomon AK. Permeability of luminal surface of intestinal mucosal cells. F Gen Physiol 1962;45:801-10.

2 Fordtran JS, Rector FC, Locklear TW, Ewton MF. Water and solute movements in the small intestine of patients with sprue. $\mathcal{f}$ Clin Invest $1976 ; 46: 287-98$.

${ }^{3}$ Menzies IS, Laker MF, Pounder R, et al. Abnormal permeability to sugars in villous atrophy. Lancet $1979 ; \mathrm{ii}: 1107-9$.

${ }^{4}$ Cobden I, Dickinson RJ, Rothwell J, Axon ATR. Intestinal permeability assessed by the excretion ratio of two molecules results in coeliac disease. $\mathrm{Br}$ Med $\mathcal{f} 1978$;ii:1060-3.

${ }^{5}$ Jackson PG, Lessof MH, Baker RWR, Ferrett J, MacDonald DM. Intestinal permeability in patients with eczema and food allergy. Lancet $1981 ; \mathrm{i}: 1285-6$.

${ }^{6}$ Beach RC, Menzies IS, Clayden GS, Scopes JW. Gastrointestinal permeability changes in the preterm neonate. Arch Dis Child 1982 57:117-22.

7 Schachter H, Kirsner JB. Definition of inflammatory bowel disease of unknown aetiology. Gastroenterology 1975;68:591-600.

${ }^{8}$ Laker MF, Mount JN. Mannitol estimation in biological fluids by gas liquid chromatography of trimethsilyl derivatives. Clin Chem 1980 26:441-3.

${ }^{9}$ Laker MF. Estimation of disaccharides in plasma and urine by gas liquid chromatography. 7 Chromatogr 1979;163:9-18.

${ }^{10}$ Laker MF. MD thesis. The effect of hypertonic solutions on the gastrointestinal permeability to disaccharide. University of London, 1978.

${ }^{11}$ Menzies IS. Absorption of intact oligosaccharides in health and disease. Biochem Soc Trans 1974;2:1042-6.

12 Dahlqvist A, Gryboski JD. Inability of the human small intestinal lactose to hydrolyse lactulose. Biochim Bipohys Acta 1965;110:635-6.

${ }^{13}$ Frömter E, Diamond J. Route of passive ion permeation in epithelia. Nature New Biology 1972;235:9-13.

14 Laker MF, Menzies IS. Increase in human intestinal permeability following ingestion of hypertonic solutions. F Physiol 1977;265:881-94

15 Wheeler PG, Menzies IS, Creamer B. Effect of hyperosmolar stimuli and coeliac disease on the permeability of the human gastrointestinal tract. Clinical Science and Molecular Medicine 1978;54:495-501.

${ }_{16}$ Cobden I, Rothwell J, Axon ATR. Intestinal permeability and screening tests for coeliac disease. Gut 1980;21:512-8.

17 Sundqvist T, Magnusson KE, Sjodahl R, Stjernstron I, Tagesson C. Passage of molecules through the wall of the gastrointestinal tract II: Application of low molecular weight polyethyleneglycol and a deterministic mathematical model for determining intestinal permeability in man. Gut $1980 ; 21: 208-14$.

(Accepted 30 April 1982) 